\title{
Genetic analysis of reproductive disorders and their relationship to fertility and milk yield in Austrian Fleckvieh dual-purpose cows
}

\author{
A. Koeck, ${ }^{* 1}$ C. Egger-Danner, $\dagger$ C. Fuerst, $\dagger$ W. Obritzhauser, $\ddagger$ and B. Fuerst-Walt| ${ }^{\star}$ \\ ${ }^{*}$ Division of Livestock Sciences, Department of Sustainable Agricultural Systems, University of Natural Resources and Applied Life Sciences, \\ Gregor-Mendel-Str. 33, 1180 Vienna, Austria \\ †ZuchtData EDV-Dienstleistungen GmbH, Dresdner Str. 89/19, 1200 Vienna, Austria \\ $\ddagger$ Chamber of Veterinaries, Biberstr. 22, 1010 Vienna, Austria
}

\section{ABSTRACT}

The objective of this study was to estimate genetic parameters for various reproductive disorders based on veterinary diagnoses for Austrian Fleckvieh (Simmental) dual-purpose cattle. The health traits analyzed included retained placenta, puerperal diseases, metritis, silent heat and anestrus, and cystic ovaries. Three composite traits were also evaluated: early reproductive disorders, late reproductive disorders, and all reproductive disorders. Heritabilities were estimated with logit threshold sire, linear sire, and linear animal models. The threshold model estimates for heritability ranged from 0.01 to 0.14 , whereas the linear model estimates were lower, ranging from 0.005 to 0.04. Rank correlations among random effects of sires from linear and threshold sire models were high $(>0.99)$, whereas correlations between any sire model (linear, threshold) and the linear animal model were lower (0.88-0.92). Genetic correlations among reproductive disorders, fertility traits, and milk yield were estimated with bivariate linear animal models. Fertility traits included interval from calving to first insemination, nonreturn rate at $56 \mathrm{~d}$, and interval between first and last insemination. Milk yield was calculated as the mean from test-day 1 and test-day 2 after calving. Estimated genetic correlations were 1 among metritis, retained placenta, and puerperal diseases and 0.85 between silent heat-anestrus and cystic ovaries. Low to moderate correlations $(-0.01$ to 0.68$)$ were obtained among the other disorders. Genetic correlations between reproductive disorders and fertility traits were favorable, whereas antagonistic relationships were observed between milk yield in early lactation and reproductive disorders. Pearson correlations between estimated breeding values for reproductive disorders and other routinely evaluated traits were computed, which revealed noticeable favorable relationships to longevity, calving ease maternal, and stillbirth maternal.

Received July 15, 2009.

Accepted January 19, 2010.

${ }^{1}$ Corresponding author: astrid.koeck@boku.ac.at
The results showed that data from the Austrian health monitoring project can be used for genetic selection against reproductive disorders in Fleckvieh cattle.

Key words: reproductive disorder, fertility, linear model, threshold model

\section{INTRODUCTION}

Functional traits such as fertility and health traits are becoming increasingly important in selection decisions worldwide because of economic reasons as well as animal welfare concerns and consumer demands for healthy and naturally produced products.

In most dairy cattle populations, the primary selection objective during the past several decades was milk production, whereas fertility and health traits received less attention (Miglior et al., 2005). As a consequence, genetic trends in fertility are negative because of an unfavorable correlated selection response (VanRaden et al., 2004; Liu et al., 2008). A slight decrease in fertility was also observed in Austrian dual-purpose breeds such as Fleckvieh (dual-purpose Simmental; Fuerst and Gredler, 2009). In contrast, genetic fertility trends are constant or even positive for the different Nordic Red breeds, arising from a simultaneous and consequent selection of bulls for production and fertility for more than 30 yr (Fogh et al., 2003; Philipsson and Lindhé, 2003; Andersen-Ranberg et al., 2005).

In Austria, genetic evaluations for fertility based on nonreturn rate at $90 \mathrm{~d}$ were carried out from 1995 to 2008; since 2002, genetic evaluations for all traits have been performed jointly with Germany for Fleckvieh cattle (Fuerst and Egger-Danner, 2002). However, female fertility has many components and cannot simply be explained by 1 trait only. Female fertility is represented by different abilities: the ability to show heat or maturity, the ability to conceive and to carry on to term, the ability to resist disorders, and the ability to recycle. Hence, in 2008 a new fertility index was introduced (Fuerst and Gredler, 2009) based on the results of Gredler (2008). Several traits are combined in this index: interval from calving to first insemination 
(CFI), nonreturn rate at $56 \mathrm{~d}$ (NR56), and interval from first to last insemination (FLI). The trait CFI describes mainly the ability of a cow to come into estrus and show heat, and NR56 and FLI are measures of the ability of a heifer or cow to conceive after insemination. The latter traits also include losses because of embryonic death. Because the physiological status of heifers is quite different from that of cows, the traits NR56 and FLI are analyzed separately for heifers and cows. The fertility index is included in the total merit index with a relative weight of $6.8 \%$ for Fleckvieh cattle (Fuerst and Gredler, 2009).

At present, no direct health traits are included in the total merit index of Austrian Fleckvieh cattle because no recording system of diseases existed until recently. A project to establish a nationwide health monitoring system for cattle was started in Austria in 2006 in which diagnoses from veterinarians are recorded (Egger-Danner et al., 2007). The main project aims are to provide support for herd management and to obtain breeding values for health traits. Health traits are, so far, routinely evaluated only in the Scandinavian countries (Interbull, 2009), where disease recording programs have been carried out on a large scale for more than $30 \mathrm{yr}$. The routine Scandinavian genetic evaluation of disease traits is based on linear models, which assume normal distribution of the data. Because diseases are treated as binary traits in genetic evaluation, nonlinear threshold models would be, at least theoretically, more appropriate for variance component and breeding value estimation (Gianola and Foulley, 1983).

Based on data from the Austrian health monitoring project, besides mastitis, reproductive disorders are the most frequent disease category in Fleckvieh cattle. Therefore, the objectives of this study were 1) to estimate heritabilities with threshold and linear models for various reproductive disorders; 2) to compare sire rankings for reproductive disorders from genetic evaluations with threshold and linear models; 3) to investigate relationships between reproductive disorders, fertility traits, and milk yield in early lactation (MY); and 4) to assess correlations between reproductive disorders and other traits that are routinely evaluated.

\section{MATERIALS AND METHODS}

\section{Data}

Health Monitoring. In Austria, under legal obligation, veterinary diagnoses and treatments have to be documented. These documents must be kept for $5 \mathrm{yr}$ by the veterinarians as well as the farmers. However, up until now these data have been neither collected nor stored in a database. Since July 2006, diagnosis data from veterinarians have been recorded in Austria within the framework of the project called "Health monitoring in cattle" (Egger-Danner et al., 2007). For this purpose, a standardized diagnosis key is used that consists of 10 disease groups (diseases of calves; diseases of the digestive tract; metabolic diseases; infertility and disorders associated with parturition; udder diseases; diseases of the claw and other diseases of the legs; diseases of the respiratory tract; cardiovascular diseases, diseases of the blood and urinary tract; diseases of the central nervous system, skin and infectious diseases; and other diseases) covering 65 different disease codes. The diagnosis data from veterinarians are collected monthly by the milk recording technicians or are sent electronically to the database by the veterinarians. The data are stored within the Austrian central cattle database (Rinderdatenverbund). Recording of health data on farms is currently voluntary.

Data Validation and Editing. A basic prerequisite for an efficient use of health data is a correct data validation. Several measures were applied to ensure adequate reporting within individual herds. Before recording the data in the database, routine plausibility checks were carried out. To distinguish farms with low frequencies of diseases from those with incomplete documentation and recording, at least 1 diagnosis per 10 cows, year, and farm must have been reported. Additionally, continuous recording and reporting by the veterinarians and farmers was a precondition. Furthermore, only data from veterinarians who recorded at least 500 diagnoses during the whole period were considered in this analysis to rule out inconsistent data collection. About $25 \%$ of the farms had to be excluded by data editing, assuming unreliable documentation and recording.

At present, about $70 \%$ of all cows participating in the Austrian milk recording scheme belong to the Fleckvieh breed (ZAR, 2009), so the analyses were carried out for this breed only. Records of 33,362 Fleckvieh cows with a maximum non-Fleckvieh gene proportion of 25\%, calving between January 1, 2007 and November 30,2008 , were used in this study. Only cows from first to fifth lactation with an age at first calving between 19 and 43 mo were included. Records of animals with a calving interval $<300 \mathrm{~d}$ or $>800 \mathrm{~d}$ were excluded.

Traits. Reproductive disorders with an incidence far below $1 \%$ were not considered in the analyses; these were uterine prolapse $(0.10 \%)$, abortion $(0.19 \%)$, injuries incidental to parturition $(0.21 \%)$, and difficult calving $(0.34 \%)$. The latter proportion is low because only veterinary-assisted calvings are included, whereas calving ease scores are reported by farmers (Fürst and Fürst-Waltl, 2006). Thus, the following disease traits were analyzed: retained placenta (RP), puerperal diseases (PUERP), metritis (MET), silent heat and anestrus (ESTRUS), and cystic ovaries (CYST). 
Table 1. Stage of lactation, measured as days after calving, for first incidence (\%) of retained placenta (RP), puerperal diseases (PUERP), metritis (MET), silent heat and anestrus (ESTRUS), and cystic ovaries (CYST) based on cows that completed $300 \mathrm{~d}$ after calving

\begin{tabular}{|c|c|c|c|c|c|}
\hline Days from calving & $\mathrm{RP}(\mathrm{n}=1,038)$ & PUERP $(\mathrm{n}=549)$ & $\operatorname{MET}(\mathrm{n}=1,024)$ & ESTRUS $(\mathrm{n}=1,889)$ & CYST $(\mathrm{n}=2,455)$ \\
\hline $8-14$ & 1.6 & 4.4 & 9.0 & 0.6 & 0.4 \\
\hline $61-90$ & 0.1 & 2.6 & 11.8 & 30.0 & 28.0 \\
\hline $91-120$ & 0.0 & 0.6 & 7.2 & 18.9 & 18.2 \\
\hline $121-150$ & 0.1 & 0.7 & 5.1 & 10.2 & 9.0 \\
\hline $211-240$ & 0.2 & 0.6 & 1.5 & 2.0 & 2.0 \\
\hline $241-270$ & 0.7 & 0.6 & 1.4 & 1.1 & 1.1 \\
\hline $271-300$ & 1.2 & 0.5 & 0.5 & 0.5 & 0.7 \\
\hline
\end{tabular}

Table 1 shows the distribution of first occurrence of each reproductive disorder according to days after calving. The majority of cases of RP and PUERP occurred within $7 \mathrm{~d}$ after calving, whereas treatments of MET were reported mainly during the first $30 \mathrm{~d}$ after calving and the breeding period. As expected, most cases of ESTRUS and CYST were treated during the breeding period. Thus, veterinary diagnoses were considered from calving to $7 \mathrm{~d}$ after calving for RP, from calving to $30 \mathrm{~d}$ after calving for PUERP, and from calving to $150 \mathrm{~d}$ after calving for MET, ESTRUS, and CYST. For MET, ESTRUS, and CYST, an additional constraint was introduced. Only cows that completed at least twothirds of the opportunity period $(100 \mathrm{~d})$ were included in the analyses. This should ensure that each cow has a sufficient chance to express the trait. Cases of ESTRUS, CYST, and MET after $150 \mathrm{~d}$ were not taken into account to avoid bias caused by culling of cows.

Besides the individual traits, 3 composite traits were also evaluated. Because of the rather low incidences for most diseases, composite traits are more suitable for genetic evaluation than single traits. A more general disease definition leads to higher incidences and possibly to more accurate estimated breeding values. The following composite traits were evaluated. All reproductive disorders that occurred within $150 \mathrm{~d}$ after calving were joined into 1 category, reproductive disorders (REPRO). The trait early reproductive disorders (EREPRO) included all reproductive disorders that were treated within $30 \mathrm{~d}$ after calving, whereas the trait late reproductive disorders (LREPRO) included all reproductive diseases occurring between 31 and 150 d after calving. The trait EREPRO consisted mainly of diseases that were associated with calving (RP, PUERP, puerperal MET), whereas the trait LREPRO was dominated by hormonal and late infectious diseases (CYST, ESTRUS, MET in late lactation). Absence or presence of each of the reproductive disorders was coded as 0 or 1 based on whether or not the cow had at least 1 veterinary treatment within a defined time interval.

The fertility traits NR56, CFI, and FLI were calculated from calving and insemination data. Insemination records were used only from cows with CFI values in the range of 20 to $300 \mathrm{~d}$. The interval between calving to last insemination had to be between 20 and 500 d. Records with FLI values longer than $300 \mathrm{~d}$ were deleted, as were records with a gestation length shorter than $270 \mathrm{~d}$ or longer than $310 \mathrm{~d}$ (breed average: $290 \mathrm{~d}$ $\pm 3 \mathrm{SD}$ ). The calculation of NR56 was based on first inseminations and the record was discarded when several inseminations had occurred within a 5-d period (double insemination). If the cow was culled within 56 $\mathrm{d}$ after first insemination, the record was excluded. The trait NR56 was scored as 0 if the cow had a second insemination within $56 \mathrm{~d}$ after the first insemination and 1 otherwise. The fertility trait FLI was considered only if a subsequent calving was present.

In Austria, milk yield is recorded on a monthly basis. For MY in early lactation, the average of test-days 1 and 2 after calving was calculated and used for genetic analyses.

All data sets were further restricted separately to include only cows from herd-year-season (for reproductive disorders) or herd-year (for fertility traits and MY) classes with at least 3 records. Seasons were January to March, April to June, July to September, and October to December. Additionally, sires were required to have at least 20 daughters. A summary of the analyzed data is given in Table 2 .

Pedigree File. A sire pedigree file was generated by tracing the pedigrees of sires and maternal grandsires 5 generations back. A total of 4,878 sires were included in this pedigree file. The animal pedigree file was generated by tracing the pedigrees of cows with data 5 generations back. The resulting pedigree file included the relationship of 183,525 animals. 
Table 2. Description of analyzed reproductive disorder, fertility, and production traits

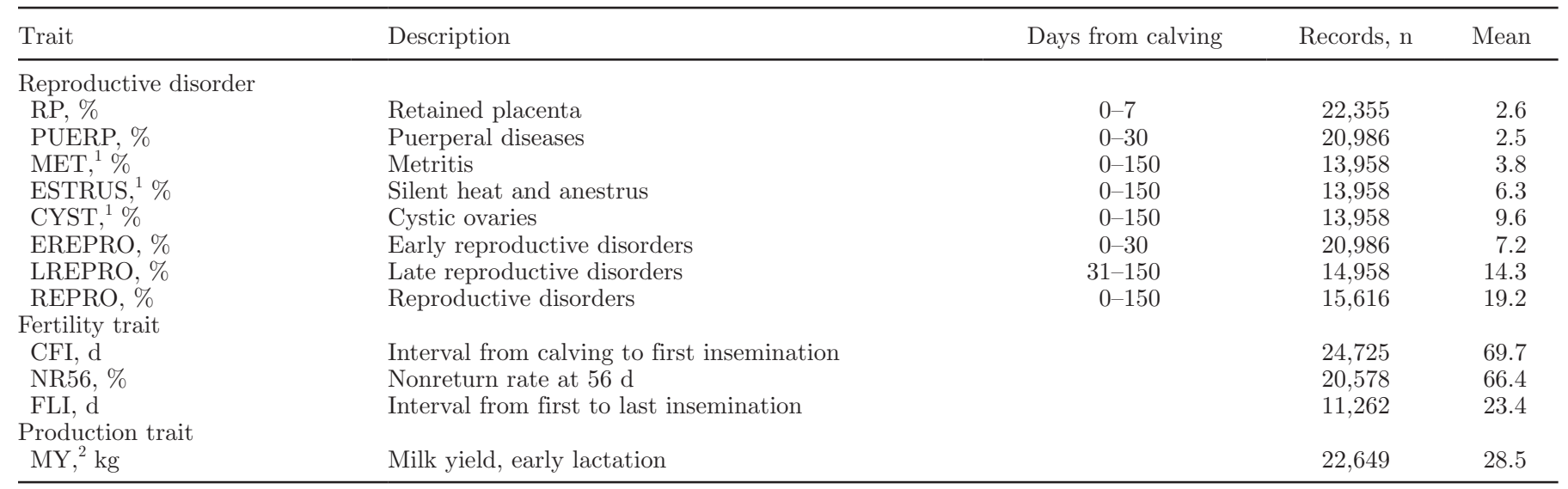

${ }^{1}$ Information of cows that completed at least two-thirds of the opportunity period $(100 \mathrm{~d})$ was considered in the data.

${ }^{2}$ Average of test-day 1 and 2 after calving.

\section{Statistical Models}

Univariate Threshold Model. The reproductive disorders RP, PUERP, MET, ESTRUS, CYST, EREPRO, LREPRO, and REPRO were analyzed using a threshold model (Wright, 1934; Gianola, 1982; Gianola and Foulley, 1983) that accounted for the binary (0, 1) nature of the data. The software package ASREML (Gilmour et al., 2006), the working algorithm of which is based on generalized linear mixed models, was used for threshold model analyses. Generalized linear mixed models are based on finding a relationship (link function) between the expected value of a random variable and a linear function of explanatory variables (Tempelman, 1998; Kachman, 2000). Variance components were estimated by applying the binomial distribution with a logit link function. In matrix notation, the threshold model was as follows:

$$
\lambda=\mathbf{X} \boldsymbol{\beta}+\mathbf{Z}_{\mathbf{h}} \mathbf{h}+\mathbf{Z}_{\mathrm{s}} \mathbf{s}+\mathbf{W} \mathbf{p}+\mathbf{e},
$$

where $\lambda$ is a vector of unobserved liabilities to RP, PUERP, MET, ESTRUS, CYST, EREPRO, LREPRO, and REPRO; $\boldsymbol{\beta}$ is a vector of systematic effects, including fixed effect of parity; $\mathbf{h}$ is a vector of random herd-year-season of calving effects; $\mathbf{s}$ is a vector of sire effects; $\mathbf{p}$ is a vector of permanent environmental effects of the cow; $\mathbf{e}$ is a vector of residuals; and $\mathbf{X}, \mathbf{Z}_{\mathbf{h}}, \mathbf{Z}_{\mathrm{s}}$, and $\mathbf{W}$ are the corresponding incidence matrices.

Because the average herd size in Austria is quite small ( $\sim 16$ cows per herd; ZAR, 2009), herd-yearseason effects were treated as random to minimize loss of information. Additionally, the well-known extreme category problems (i.e., all observations in individual subclasses are either 0 or 1 ) of the threshold model that occur especially in traits with low incidences are allevi- ated by using random effects (Sorenson and Gianola, 2002). The threshold model analyses were based on a sire model because the generalized linear mixed model methodology for binary threshold traits is not reliable under an animal model (Gilmour et al., 2006).

Heritabilities were calculated using the variance of the logit link function. This requires a correction of the residual variance by the factor $\pi^{2} / 3$. Thus, heritability was calculated as follows:

$$
h^{2}=\frac{4 \sigma_{s}^{2}}{\sigma_{s}^{2}+\sigma_{h}^{2}+\sigma_{p}^{2}+\pi^{2} / 3} .
$$

Univariate Linear Model. For comparison, reproductive disorders (RP, PUERP, MET, ESTRUS, CYST, EREPRO, LREPRO, and REPRO) were analyzed with linear sire and linear animal models. To obtain REML estimates of the variance components, the VCE6 package was used (Groeneveld et al., 2008). The fixed and random effects for these traits were as described above.

Bivariate Linear Model. Genetic correlations were calculated with bivariate linear animal models. Genetic correlations were calculated 1) between single traits (RP, PUERP, MET, ESTRUS, and CYST), and 2) between composite traits (EREPRO, LREPRO, REPRO), fertility (NR56, CFI, FLI), and MY in early lactation. Linear animal models were applied because the number of observations was low and animal models use information from all known relationships. Besides, genetic correlations are reported to be correct for binary traits using linear models (Heringstad et al., 2005; Negussie et al., 2008). The model used for reproductive disorders was as given above. For NR56, CFI, FLI, and MY, the following model was applied: 


$$
\mathbf{y}=\mathbf{X} \boldsymbol{\beta}+\mathbf{Z}_{\mathbf{h}} \mathbf{h}+\mathbf{Z}_{\mathbf{a}} \mathbf{a}+\mathbf{W} \mathbf{p}+\mathbf{e},
$$

where $\mathbf{y}$ is a vector of observations for NR56, CFI, FLI, and MY; $\boldsymbol{\beta}$ is a vector of systematic effects, including fixed effects of age at calving-parity interaction for all traits, year-month of insemination for NR56, and yearmonth of calving for CFI, FLI, and MY; $\mathbf{h}$ is a vector of random herd-year of insemination effects for NR56 and herd-year of calving effects for CFI, FLI, and MY; $\mathbf{a}$ is a vector of animal effects; $\mathbf{p}$ is a vector of permanent environmental effects of the cow; $\mathbf{e}$ is a vector of residuals; and $\mathbf{X}, \mathbf{Z}_{\mathrm{h}}, \mathbf{Z}_{\mathrm{a}}$, and $\mathbf{W}$ are the corresponding incidence matrices.

Calving age classes were formed for each of the first 2 parities. Age at first calving had 14 classes in which $<25$ mo was the first class, $\geq 37$ mo was the last class, and other classes were single months. Age at second calving was grouped into 15 classes in which $<37$ mo was the first class, $\geq 50$ mo was the last class, and other classes were single months. For older cows, age-parity classes were parity 3,4 , and 5 .

Service sire was not considered in the model for NR56. In Austrian dual-purpose Fleckvieh cattle, Gredler (2008) found that service sires accounted for only a very small fraction $(0.2-0.4 \%)$ of the phenotypic variation.

\section{Genetic Evaluations}

Breeding values for the composite traits EREPRO, LREPRO, and REPRO based on linear animal models were estimated by using the software package PEST (Groeneveld, 2006). The resulting genetic solutions were reversed in sign. Thus, higher breeding values indicate genetically favorable sires with fewer diseased daughters. In accordance to the Austrian routine breeding value estimation, EBV were standardized to relative breeding values with a mean of 100 and a genetic standard deviation of 12 points. Pearson correlations between breeding values of sires with at least 50 daughters for EREPRO, LREPRO, and REPRO with other traits that are routinely evaluated were computed.

\section{RESULTS AND DISCUSSION}

\section{Descriptive Statistics}

Phenotypic values for the analyzed traits are shown in Table 2. The incidences of RP, PUERP, MET, ESTRUS, CYST, EREPRO, LREPRO, and REPRO within the defined time periods were $2.6,2.5,3.8,6.3$, $9.6,7.2,14.3$, and $19.2 \%$, respectively, across the first 5 lactations of Austrian Fleckvieh cows. The average for NR56 was $66.4 \%$. Mean values for CFI and FLI were 69.7 and $23.4 \mathrm{~d}$, respectively. Because the mean value for FLI was lower than in earlier studies (Gredler, 2008), the results involving FLI should be interpreted with caution. The average milk yield from test-days 1 and 2 after calving was $28.5 \mathrm{~kg}$.

\section{Heritabilities}

Estimates of heritability from logit threshold model analyses are given in Table 3. Heritabilities were 0.06, 0.14, 0.06, 0.01, and 0.08 for RP, PUERP, MET, ESTRUS, and CYST, respectively. For the composite traits EREPRO, LREPRO, and REPRO, heritabilities of $0.08,0.05$, and 0.05 , respectively, were estimated. The heritability estimates of composite traits were slightly lower than the estimates of single traits. There is a loss of information about genetic variation when single traits are pooled into composite traits. However, standard errors were lower for composite than for single traits. The results are generally in agreement with other studies, despite slightly different trait definitions and models. Wassmuth et al. (2000) found heritability estimates of RP transformed to the underlying liability scale of $0.03,0.09$, and 0.10 for Danish Jersey, Danish Holstein, and Danish Red, respectively. Other estimates of heritability of RP from threshold models range from 0.06 to 0.09 (Heringstad, 2009a; Heringstad et al., 2009b). For PUERP, no heritability estimates were available in the literature. Pösö and Mäntysaari (1996) found heritability estimates transformed to the liability scale ranging from 0.02 to 0.05 for ovulatory disorders and 0.04 to 0.05 for metritis. Zwald et al. (2004a) obtained heritabilities of 0.07 and 0.05 for MET and CYST, respectively, from threshold model analyses that included all available lactation records. Considering only first-lactation cows, they found slightly higher heritabilities. In first-lactation Norwegian Red cattle, Heringstad (2009a) reported heritabilities of 0.03 and 0.07 for MET and CYST, respectively. For ESTRUS, Heringstad (2009a) obtained a heritability of 0.06 , which is higher than our estimate.

As expected, the heritability estimates from the linear model analyses were lower and ranged from 0.005 to 0.04 (Table 3 ). However, the results from linear and logit threshold models cannot be compared directly because the estimates are on a different scale. The estimates of logit threshold models are expressed on the underlying logistic scale, whereas the estimates of linear models are on the observable scale. Overall, the heritability estimates from the linear model analyses were in the range of previous studies (Pösö and Mäntysaari, 1996; Van Dorp et al., 1998; Wassmuth et al., 2000; Dechow et al., 2004). 
Table 3. Estimated heritabilities for retained placenta (RP), puerperal diseases (PUERP), metritis (MET), silent heat and anestrus (ESTRUS), cystic ovaries (CYST), early reproductive disorders (EREPRO), late reproductive disorders (LREPRO), and reproductive disorders (REPRO) based on logit threshold sire models (TSM), linear sire models (LSM), and linear animal models (LAM) ${ }^{1}$

\begin{tabular}{lccc}
\hline Trait & TSM & LSM & LAM \\
\hline Single trait & & & \\
RP & $0.060(0.037)$ & $0.006(0.004)$ & $0.007(0.004)$ \\
PUERP & $0.143(0.054)$ & $0.017(0.006)$ & $0.019(0.005)$ \\
MET & $0.062(0.036)$ & $0.012(0.006)$ & $0.009(0.004)$ \\
ESTRUS & $0.012(0.015)$ & $0.005(0.004)$ & $0.006(0.004)$ \\
CYST & $0.077(0.027)$ & $0.031(0.010)$ & $0.040(0.009)$ \\
Composite trait & & & \\
EREPRO & $0.079(0.025)$ & $0.021(0.007)$ & $0.023(0.006)$ \\
LREPRO & $0.048(0.018)$ & $0.026(0.009)$ & $0.035(0.009)$ \\
REPRO & $0.050(0.016)$ & $0.031(0.009)$ & $0.039(0.010)$ \\
\hline
\end{tabular}

${ }^{1}$ Standard errors for the estimates are shown in parentheses.

\section{Threshold and Linear Models}

An important question is to what extent the ranking of sires for various reproductive disorders agrees across models. For this purpose, rank correlations between random effects of sires with progeny in the data set from logit threshold sire, linear sire, and linear animal models were compared (Table 4). The correlations between random effects of sires obtained with linear sire and threshold sire models were $>0.99$, whereas correlations between any sire model (linear, threshold) and the animal model were lower $(\mathrm{r}=0.88-0.92)$ for all traits. The effects associated with applying an animal model instead of a sire model were more important than the differences resulting from the different methodology (linear or threshold model). The study from Boettcher et al. (1999) showed that the EBV of sires from linear sire and threshold sire models were highly correlated $(\mathrm{r}=0.98)$, whereas the correlations between animal models and linear sire or threshold sire models were 0.87 and 0.86, respectively. Furthermore, Vazquez et al. (2009) carried out a cross validation to assess the predictive ability of logit sire and linear sire models for mastitis. The correlations between the expected values of logit and linear models were 0.998 , which suggest equal overall predictive performance for both models.

\section{Genetic Correlations Between Reproductive Disorders}

Genetic correlations between single traits (RP, PUERP, MET, ESTRUS, and CYST) are shown in Table 5. The traits RP, PUERP, and MET in early lactation (puerperal metritis) are considered to be related. It is well known that RP increases the risk of uterine infections after calving (LeBlanc, 2008). However, the obtained genetic correlation of 1 between RP, PUERP, and MET was surprising. This may imply that veterinarians partly did not distinguish precisely between these codes. Other studies have reported much lower correlations among these traits. Lin et al. (1989) found a genetic correlation of 0.24 between RP and MET in first-lactation cows, whereas in the study of Van Dorp et al. (1998) the estimates of genetic correlations between RP and MET were positive but close to 0. Using field data of more than 500,000 first-lactation Norwegian Red cows, Heringstad (2009a) estimated a

Table 4. Rank correlations between random effects of sires with progeny in the data set for retained placenta (RP), puerperal diseases (PUERP), metritis (MET), silent heat and anestrus (ESTRUS), cystic ovaries (CYST), early reproductive disorders (EREPRO), late reproductive disorders (LREPRO), and reproductive disorders (REPRO) based on logit threshold sire models (TSM), linear sire models (LSM), and linear animal models (LAM)

\begin{tabular}{lcccc}
\hline Trait & Sires, $\mathrm{n}$ & TSM-LSM & TSM-LAM & LSM-LAM \\
\hline Single trait & & & & \\
RP & 253 & 0.999 & 0.882 & 0.880 \\
PUERP & 240 & 0.994 & 0.884 & 0.891 \\
MET & 173 & 0.996 & 0.913 & 0.914 \\
ESTRUS & 173 & 0.993 & 0.876 & 0.887 \\
CYST & 173 & 0.995 & 0.905 & 0.914 \\
Composite trait & & & & 0.922 \\
EREPRO & 240 & 0.998 & 0.821 & 0.899 \\
LREPRO & 182 & 0.996 & 0.920 & 0.923 \\
REPRO & 186 & 0.995 & & \\
\hline
\end{tabular}


Table 5. Estimated parameters for retained placenta (RP), puerperal diseases (PUERP), metritis (MET), silent heat and anestrus (ESTRUS), and cystic ovaries (CYST) based on linear animal models ${ }^{1}$

\begin{tabular}{lcccrr}
\hline Trait & \multicolumn{1}{c}{ RP } & \multicolumn{1}{c}{ PUERP } & \multicolumn{1}{c}{ MET } & \multicolumn{1}{c}{ ESTRUS } & \multicolumn{1}{c}{ CYST } \\
\hline RP & $0.007(0.003)$ & $1.000(<0.001)$ & $1.000(<0.001)$ & $0.388(0.084)$ & $-0.014(0.180)$ \\
PUERP & & $0.019(0.005)$ & $1.000(0.001)$ & $0.466(0.139)$ & $0.676(0.114)$ \\
MET & & & $0.010(0.005)$ & $0.054(0.443)$ & $0.217(0.235)$ \\
ESTRUS & & & $0.006(0.004)$ & $0.849(0.280)$ \\
CYST & & & & & $0.041(0.010)$ \\
\hline
\end{tabular}

${ }^{1}$ Heritabilities are on the diagonal and genetic correlations are above the diagonal. Standard errors for the estimates are shown in parentheses.

genetic correlation of 0.64 between MET within $300 \mathrm{~d}$ after calving and RP.

Low to moderate genetic correlations were found between ESTRUS and RP, PUERP, and MET, whereas a strong positive correlation of 0.85 was found between ESTRUS and CYST. As reviewed by Garverick (1997) and Vanholder et al. (2006), the clinical signs that accompany ovarian cysts are variable, but many cows with cysts are recognized to be anestrus. Heringstad (2009a) reported that all genetic correlations in Norwegian Red cows involving ESTRUS (RP, MET, CYST) were low and that none of the genetic correlations could be considered to be different from 0 .

There was no significant genetic correlation between CYST and RP and MET, which is in agreement with previous studies of Van Dorp et al. (1998) and Zwald et al. (2004b). In the study of Heringstad (2009a), genetic correlations between CYST and MET were not different from zero, whereas between CYST and RP a negative correlation of -0.26 was found.

In the current study, a strong positive genetic correlation of 0.68 was estimated between CYST and PUERP. Genetic correlations involving PUERP were, however, not available in the literature.

Genetic correlations among the composite traits EREPRO, LREPRO, and REPRO are presented in Table 6. A moderately positive genetic correlation of 0.57 was found between EREPRO and LREPRO. This was expected because genetic correlations between individual reproductive disorders that appear in early lactation and those in late lactation were low to moderate (Table 5). The differentiation between EREPRO and LREPRO is also reasonable; based on the results of our study, the traits that occur mainly around calving (RP, PUERP, MET) were highly correlated and CYST and ESTRUS also seem to share the same genetic background to a great extent. However, between the hormonal diseases (CYST, ESTRUS) and MET, an inflammation of the uterus, a low genetic correlation was found. Thus, for genetic evaluation, reproductive disorders should be regarded as different traits, at least in early and later stages of lactation, as it has been developed for the joint genetic evaluation in Denmark, Sweden, and Finland (Johansson et al., 2008). Johansson et al. (2008) reported even lower genetic correlations ranging from 0.25 to 0.40 between EREPRO and LREPRO in the first 3 lactations for Danish Holstein and Red Danish cattle.

\section{Genetic Correlations with Fertility and Milk Yield}

Genetic correlations between EREPRO, LREPRO, REPRO, fertility (NR56, CFI, FLI), and MY in early lactation are given in Table 6. Estimates of genetic correlations between disease and fertility traits were all favorable. Low to moderate genetic correlations were found between CFI and the different disease traits. Genetic correlations between NR56 and EREPRO, LREPRO, and REPRO were in the range from -0.40 to -0.87 . Even higher favorable correlations were

Table 6. Estimated parameters for early reproductive disorders (EREPRO), late reproductive disorders (LREPRO), reproductive disorders (REPRO), interval from calving to first insemination (CFI), nonreturn rate at $56 \mathrm{~d}$ (NR56), interval from first to last insemination (FLI), and milk yield (MY) based on linear animal models ${ }^{1}$

\begin{tabular}{|c|c|c|c|c|c|c|c|}
\hline Trait & EREPRO & LREPRO & REPRO & CFI & NR56 & FLI & MY \\
\hline LREPRO & & $0.037(0.009)$ & $0.959(0.020)$ & $0.525(0.127)$ & $-0.865(0.134)$ & $0.826(0.099)$ & $0.209(0.078)$ \\
\hline NR56 & & & & & $0.008(0.004)$ & $-0.930(0.132)$ & $-0.587(0.130)$ \\
\hline FLI & & & & & & $0.014(0.006)$ & $0.441(0.192)$ \\
\hline MY & & & & & & & $0.190(0.013)$ \\
\hline
\end{tabular}

${ }^{1}$ Heritabilities are on the diagonal and genetic correlations are above the diagonal. Standard errors for the estimates are shown in parentheses. 
Table 7. Pearson correlations between EBV of sires with at least 50 daughters for early reproductive disorders (EREPRO), late reproductive disorders (LREPRO), and reproductive disorders (REPRO) based on linear animal models and EBV for other traits routinely evaluated

\begin{tabular}{|c|c|c|c|}
\hline Item & $\begin{array}{l}\text { EREPRO } \\
\text { (109 sires) }\end{array}$ & $\begin{array}{c}\text { LREPRO } \\
\text { (92 sires) }\end{array}$ & $\begin{array}{l}\text { REPRO } \\
(94 \text { sires })\end{array}$ \\
\hline Milk, kg & -0.05 & -0.15 & -0.07 \\
\hline Fat, $\%$ & 0.04 & 0.13 & 0.08 \\
\hline Fat, kg & -0.02 & -0.05 & -0.01 \\
\hline Protein, \% & 0.05 & 0.07 & 0.03 \\
\hline Protein, kg & -0.02 & -0.14 & -0.07 \\
\hline Longevity & $0.27^{* *}$ & 0.13 & $0.27 * *$ \\
\hline Persistency & 0.11 & 0.02 & 0.11 \\
\hline Nonreturn rate at 56 d (heifers) & -0.10 & 0.00 & -0.07 \\
\hline Nonreturn rate at $56 \mathrm{~d}$ (cows) & -0.03 & 0.04 & -0.03 \\
\hline Interval from calving to first insemination & $0.21^{*}$ & $0.30 * *$ & $0.34^{* *}$ \\
\hline Interval from first to last insemination (heifers) & 0.00 & 0.16 & 0.11 \\
\hline Interval from first to last insemination (cows) & $0.23^{*}$ & $0.29 * *$ & $0.32^{* *}$ \\
\hline Calving ease direct & -0.15 & -0.06 & -0.01 \\
\hline Calving ease maternal & $0.37^{* * *}$ & $0.21^{*}$ & $0.28^{* *}$ \\
\hline Stillbirth direct & -0.02 & 0.02 & 0.14 \\
\hline Stillbirth maternal & $0.22^{*}$ & 0.10 & $0.21^{*}$ \\
\hline
\end{tabular}

${ }^{*} P<0.05 ;{ }^{* *} P<0.01 ;{ }^{* * *} P<0.001$.

obtained between FLI and reproductive disorders. The literature lacks studies of genetic relationships of reproductive disorders with fertility traits. Pösö and Mäntysaari (1996) found genetic correlations of 0.80 and 0.37 , the latter, however, not being significantly different from zero, between days open and ovulatory disorders and MET, respectively. Schnitzenlehner et al. (1998) reported a genetic correlation of 0.54 between $\mathrm{RP}$ and days open. Low genetic correlations of 0.24 and 0.11 between RP and CFI and between RP and NR56, respectively, were obtained by Heringstad et al. (2009b). However, the estimates from the latter study were not significantly different from zero.

Genetic correlations between MY in early lactation and EREPRO, LREPRO, and REPRO were in the range of 0.21 to 0.31 , suggesting that selection for higher milk yield would increase susceptibility to reproductive disorders. Pösö and Mäntysaari (1996) found higher unfavorable genetic associations of 0.42 and 0.68 between 305-d MY and ovulatory disorders and MET, respectively. Hooijer et al. (2001) reported a genetic correlation of 0.34 between 305-d MY and CYST. Genetic correlations among fertility (NR56, CFI, and FLI) and MY in early lactation were generally in agreement with previous estimates in Austrian Fleckvieh cattle (Gredler, 2008).

\section{Correlations of Breeding Values with Production and Fitness Traits}

Pearson correlations between breeding values of sires with at least 50 daughters for EREPRO (109 sires), LREPRO (92 sires), and REPRO (94 sires) based on linear animal models with official breeding values for production and fitness traits are shown in Table 7 . Correlations between breeding values are always an underestimation of genetic correlations unless accuracies of EBV are close to 1 . Thus, these results should be interpreted only as general indications. Again, it should be noted that higher breeding values indicate genetically favorable sires with fewer diseased daughters.

Low, but nonsignificant, antagonistic relationships were observed between milk production and all reproductive disease traits. Positive correlations were found with longevity, suggesting that selection for disease resistance would improve longevity as well, which is in agreement with the study of Zwald et al. (2004b).

Because the physiological status of heifers is quite different from that of cows, it was not unexpected that heifer fertility traits showed low positive or even negative correlations to disease resistance traits in cows. Larger positive correlations were calculated when fertility traits of cows were considered. As soon as an adequate number of diagnoses are available for heifers, these should also be included in further analyses. Further, positive correlations were found between reproductive disorders and calving ease maternal and stillbirth maternal, indicating that cows with easier and normal calving have fewer reproductive problems. A low positive, albeit nonsignificant, genetic relationship between retained placenta and calving difficulties has been shown earlier by Schnitzenlehner et al. (1998). Other genetic studies dealing with these traits were not available in the literature.

\section{CONCLUSIONS}

The results showed that the data from the Austrian health monitoring project can be used for genetic evalu- 
ation of reproductive disorders. Generally, heritability estimates of reproductive disorders are low regardless of the applied methodology (threshold or linear). Although linear models ignore the binary nature of disease traits, high rank correlations among random effects of sires obtained with linear and threshold models were calculated. Linear models have been found to be robust against deviations of the assumptions of normal distribution. All genetic correlations between reproductive disorders and fertility traits in Austrian Fleckvieh cattle were favorable. Thus, selection against reproductive disorders will result in improvement of fertility. As a correlated selection response, this would lead to higher NR56 and shorter CFI and FLI. Breeding mainly for higher MY in early lactation would lead to increased susceptibility to reproductive disorders.

This study was based on a relatively small data set, so the genetic parameters could not be estimated precisely. Therefore, it is important to reestimate these parameters as soon as a larger data set is available and to include reproductive disorders and fertility traits of heifers. Moreover, the genetic relationships between calving ease, stillbirth, and reproductive disorders should be investigated in further studies.

\section{ACKNOWLEDGMENTS}

We gratefully acknowledge the collaborative work of the project partners in Austria [Federation of Austrian Cattle Breeders, including its member organizations of performance recording and breeding (Vienna, Austria), University of Natural Resources and Applied Life Sciences (Vienna, Austria), University of Veterinary Sciences (Vienna, Austria), Chamber of Agriculture (Vienna, Austria), Chamber of Veterinaries (Vienna, Austria), and Coordination Office of Animal Health Organizations (St. Pölten, Austria)] to establish a "health monitoring system in cattle" and all participating dairy farmers and veterinarians. This work was financed by the Austrian Federal Ministry of Agriculture, Forestry, Environment and Water Management (Vienna) and the Federation of Austrian Cattle Breeders (Vienna). Birgit Fuerst-Waltl was supported by the Austrian Science Foundation (Vienna; Elise-Richter Program V43-B12). The authors thank Arthur R. Gilmour (NSW Department of Primary Industries, Orange, Australia) and 2 anonymous reviewers for their valuable comments and suggestions.

\section{REFERENCES}

Andersen-Ranberg, I. M., G. Klemetsdal, B. Heringstad, and T. Steine. 2005. Heritabilities, genetic correlations, and genetic change for female fertility and protein yield in Norwegian dairy cattle. J. Dairy Sci. 88:348-355.

Boettcher, P. J., L. K. Jairath, and J. C. M. Dekkers. 1999. Comparison of methods for genetic evaluation of sires for survival of their daughters in the first three lactations. J. Dairy Sci. 82:10341044 .

Dechow, C. D., G. W. Rogers, U. Sander-Nielsen, L. Klei, T. J. Lawlor, J. S. Clay, A. E. Freeman, G. Abdel-Azim, A. Kuck, and S. Schnell. 2004. Correlations among body condition scores from various sources, dairy form, and cow health from the United States and Denmark. J. Dairy Sci. 87:3526-3533.

Egger-Danner, C., B. Fuerst-Waltl, W. Holzhacker, R. Janacek, J. Lederer, C. Litzllachner, C. Mader, M. Mayerhofer, J. Miesenberger, W. Obritzhauser, G. Schoder, and A. Wagner. 2007. Establishing a health monitoring system for cattle in Austria: First experiences. Page 363 in Book of Abstracts of the 58th Annual Meeting of the EAAP, Dublin, Ireland. Wageningen Academic Publishers, Wageningen, the Netherlands.

Fogh, A., A. Roth, O. M. Pedersen, J. Å. Eriksson, J. Juga, M. Toivonen, I. M. Andersen-Ranberg, T. Steine, U. S. Nielsen, and G. P. Aamand. 2003. A joint Nordic model for fertility traits. Interbull Bull. 31:52-55.

Fuerst, C., and C. Egger-Danner. 2002. Joint genetic evaluation for fertility in Austria and Germany. Interbull Bull. 29:73-76.

Fuerst, C., and B. Gredler. 2009. Genetic evaluation for fertility in Austria and Germany. Interbull Bull. 40:3-9.

Fürst, C., and B. Fürst-Waltl. 2006. Züchterische Aspekte zu Kalbeverlauf, Totgeburtenrate und Nutzungsdauer in der Milchviehzucht. Züchtungskunde 78:365-383.

Garverick, H. A. 1997. Ovarian follicular cysts in dairy cows. J. Dairy Sci. 80:995-1004.

Gianola, D. 1982. Theory and analysis of threshold characters. J. Anim. Sci. 54:1079-1096.

Gianola, D., and J. L. Foulley. 1983. Sire evaluation for ordered categorical data with a threshold model. Genet. Sel. Evol. $15: 201-224$.

Gilmour, A. R., B. J. Gogel, B. R. Cullis, and R. Thompson. 2006. ASReml User Guide. Release 2.0. VSN International Ltd, Hemel Hempstead, UK.

Gredler, B. 2008. Entwicklung einer Zuchtwertschätzung für Merkmale der Fruchtbarkeit beim Rind. PhD Thesis. University of Natural Resources and Applied Life Sciences, Vienna, Austria.

Groeneveld, E. 2006. PEST User's Manual. Institute of Animal Science, Neustadt, Germany.

Groeneveld, E., M. Kovač, and N. Mielenz. 2008. VCE Users's Guide and Reference Manual. Version 6.0. Institute of Farm Animal Genetics, Neustadt, Germany.

Heringstad, B. 2009a. Genetic analysis of reproductive diseases and disorders in Norwegian Red cows. Page 179 in Book of Abstracts of the 60th Annual Meeting of the EAAP, Barcelona, Spain. Wageningen Academic Publishers, Wageningen, the Netherlands.

Heringstad, B., Y. M. Chang, D. Gianola, and G. Klemetsdal. 2005. Genetic association between susceptibility to clinical mastitis and protein yield in Norwegian dairy cattle. J. Dairy Sci. 88:1509 1514.

Heringstad, B., X.-L. Wu, and D. Gianola. 2009b. Inferring relationships between health and fertility in Norwegian Red cows using recursive models. J. Dairy Sci. 92:1778-1784.

Hooijer, G. A., R. B. F. Lubbers, B. J. Ducro, J. A. M. van Arendonk, L. M. T. E. Kaal-Lansbergen, and T. van der Lende. 2001. Genetic parameters for cystic ovarian disease in Dutch Black and White dairy cattle. J. Dairy Sci. 84:286-291.

Interbull. 2009. Description of national genetic evaluation systems for dairy cattle traits as practised in different Interbull member countries. http://www-interbull.slu.se/national_ges_info2/ framesida-ges.htm Accessed Feb. 15, 2010.

Johansson, K., J. Pösö, U. S. Nielsen, J.-À. Eriksson, and G. P. Aamand. 2008. Joint genetic evaluation of other disease traits in Denmark, Finland and Sweden. Interbull Bull. 38:107-112. 
Kachman, S. D. 2001. An introduction to generalized linear mixed models. Pages 59-73 in Proc. Implementation Strategies for National Beef Cattle Evaluation. NCR Coordinating Committee Symposium, Athens, GA. http://statistics.unl.edu/faculty/steve/ glmm/paper.pdf Accessed Feb. 15, 2010.

LeBlanc, S. J. 2008. Postpartum uterine disease and dairy herd reproductive performance. Vet. J. 176:102-114.

Lin, H. K., P. A. Oltenacu, L. D. Van Vleck, H. N. Erb, and R. D. Smith. 1989. Heritabilities of and genetic correlations among six health problems in Holstein cows. J. Dairy Sci. 72:180-186.

Liu, Z., J. Jaitner, F. Reinhardt, E. Pasman, S. Rensing, and R. Reents. 2008. Genetic evaluation of fertility traits of dairy cattle using a multiple-trait animal model. J. Dairy Sci. 91:4333-4343.

Miglior, F., B. L. Muir, and B. J. Van Doormaal. 2005. Selection indices in Holstein cattle of various countries. J. Dairy Sci. 88:1255-1263.

Negussie, E., I. Strandén, and E. A. Mäntysaari. 2008. Genetic analysis of liability to clinical mastitis, with somatic cell score and production traits using bivariate threshold-linear and linear-linear models. Livest. Sci. 117:52-59.

Philipsson, J., and B. Lindhé. 2003. Experiences of including reproduction and health traits in Scandinavian dairy cattle breeding programmes. Livest. Prod. Sci. 83:99-112.

Pösö, J., and E. A. Mäntysaari. 1996. Genetic relationships between reproductive disorders, operational days open and milk yield. Livest. Prod. Sci. 46:41-48.

Schnitzenlehner, S., A. Essl, and J. Sölkner. 1998. Retained placenta: Estimation of nongenetic effects, heritability and correlations to important traits in cattle. J. Anim. Breed. Genet. 115:467-478.

Sorenson, D., and D. Gianola. 2002. Likelihood, Bayesian and MCMC Methods in Quantitative Genetics. Springer-Verlag, New York, NY.

Tempelman, R. J. 1998. Generalized linear mixed models in dairy cattle breeding. J. Dairy Sci. 81:1428-1444.
Van Dorp, T. E., J. C. M. Dekkers, S. W. Martin, and J. P. T. M. Noordhuizen. 1998. Genetic parameters of health disorders, and relationships with 305-day milk yield and conformation traits of registered Holstein cows. J. Dairy Sci. 81:2264-2270.

Vanholder, T., G. Opsomer, and A. DeKruif. 2006. Aetiology and pathogenesis of cystic ovarian follicles in dairy cattle: A review. Reprod. Nutr. Dev. 46:105-119.

VanRaden, P. M., A. H. Sanders, M. E. Tooker, R. H. Miller, H. D. Norman, M. T. Kuhn, and G. R. Wiggans. 2004. Development of a national genetic evaluation for cow fertility. J. Dairy Sci. $87: 2285-2292$

Vazquez, A. I., D. Gianola, D. Bates, K. A. Weigel, and B. Heringstad. 2009. Assessment of poisson, logit, and linear models for genetic analysis of clinical mastitis in Norwegian Red cows. J. Dairy Sci. 92:739-748.

Wassmuth, R., D. Boelling, P. Madsen, J. Jensen, and B. B. Andersen. 2000. Genetic parameters of disease incidence, fertility and milk yield of first parity cows and the relation to feed intake of growing bulls. Acta Agric. Scand. Anim. Sci. 50:93-102.

Wright, S. 1934. An analysis of variability in number of digits in an inbred strain of guinea pigs. Genetics 19:506-536.

ZAR. 2009. Die österreichische Rinderzucht 2008. Zentrale Arbeitsgemeinschaft österreichischer Rinderzüchter (ZAR), Vienna. http://www.zar.at/article/articleview/16/1/306 Accessed September 30, 2009.

Zwald, N. R., K. A. Weigel, Y. M. Chang, R. D. Welper, and J. S. Clay. 2004a. Genetic selection for health traits using producerrecorded data. I. Incidence rates, heritability estimates, and sire breeding values. J. Dairy Sci. 87:4287-4294.

Zwald, N. R., K. A. Weigel, Y. M. Chang, R. D. Welper, and J. S. Clay. 2004b. Genetic selection for health traits using producerrecorded data. II. Genetic correlations, disease probabilities, and relationships with existing traits. J. Dairy Sci. 87:4295-4302 